\title{
Developing effective child death review: a study of 'early starter' child death overview panels in England
}

\author{
Peter Sidebotham, ${ }^{1}$ John Fox ${ }^{2}$ Jan Horwath, ${ }^{3}$ Catherine Powell ${ }^{4}$
}

${ }^{1}$ Health Sciences Research Institute, University of Warwick, Coventry, UK

Independent Trainer,

Hampshire, UK

${ }^{3}$ University of Sheffield,

Department of Sociological

Studies, Sheffield, UK

${ }^{4}$ Portsmouth City Teaching PCT,

Portsmouth, UK

\section{Correspondence to}

Dr Peter Sidebotham, Health

Sciences Research Institute,

University of Warwick, Coventry

CV4 7AL, UK:

p.sidebotham@warwick.ac.uk

Accepted 21 June 2010

\section{ABSTRACT}

Aim This qualitative study of a small number of child death overview panels aimed to observe and describe their experience in implementing new child death review processes, and making prevention recommendations.

Methods Nine sites reflecting a geographic and demographic spread were selected from Local Safeguarding Children Boards across England. Data were collected through a combination of questionnaires, interviews, structured observations, and evaluation of documents. Data were subjected to qualitative analysis. Results Data analysis revealed a number of themes within two overarching domains: the systems and structures in place to support the process; and the process and function of the panels. The data emphasised the importance of child death review being a multidisciplinary process involving senior professionals; that the process was resource and time intensive; that effective review requires both quantitative and qualitative information, and is best achieved through a structured analytic framework; and that the focus should be on learning lessons, not on trying to apportion blame. In 17 of the 24 cases discussed by the panels, issues were raised that may have indicated preventable factors. A number of examples of recommendations relating to injury prevention were observed including public awareness campaigns, community safety initiatives, training of professionals, development of protocols, and lobbying of politicians.

Conclusions The results of this study have helped to inform the subsequent establishment of child death overview panels across England. To operate effectively, panels need a clear remit and purpose, robust structures and processes, and committed personnel. A multiagency approach contributes to a broader understanding of and response to children's deaths.

\section{BACKGROUND}

In April 2008 new procedures for reviewing child deaths were instituted across England. Under the Children Act (2004) and subsequent national guidance, each local authority was required to establish a child death overview panel (CDOP) to review all deaths of children from birth to 18 years normally resident in their area. ${ }^{1} 2$ These panels were intended to improve the identification of deaths related to child maltreatment, to identify wider matters of concern affecting the safety and welfare of children in their area, and to identify any wider public health or safety concerns arising from a particular death or a pattern of deaths in that area. ${ }^{1}$ As such, they had a clear public health remit related to preventing future child deaths, including deaths from injury. Although there was some evidence that child death reviews can be effective in providing contemporary information on patterns of child death and promote action to prevent child deaths, ${ }^{3-7}$ before this there was limited experience in the UK of carrying out such reviews. In order to support the development of child death review systems in England, we carried out a qualitative study of a small number of 'early starter' CDOPs. ${ }^{8}$

\section{METHODS}

The overall aim of the study was to observe and describe the experience of authorities in implementing child death review processes, in order to inform the wider introduction of these processes. Within this overall aim, the study team sought to evaluate four basic components of the child death review processes:

A. Establishing systems-experience in establishing the mandate, protocols, membership and leadership, and operational practices of the CDOP

B. Data collection - an evaluation of systems for notification and data collection

C. Data analysis-comparison of different tools used for analysing the data collected, and approaches to identifying trends, patterns and issues

D. Outputs of the child death review processeshow authorities planned to use the information to inform children's services planning and interagency working to safeguard and promote the welfare of children.

The research team consisted of experienced academics and practitioners representing health, social care, and policing and was supported by a wider project advisory group from a range of backgrounds in policy, practice, and academia. The core research team was involved in all aspects of the study, including visiting and observing the panels and analysing the data.

Nine study sites were selected from all Local Safeguarding Children Boards (LSCBs) in England who responded to an initial questionnaire, in order to reflect a diversity of geography, population, ethnic composition, and levels of deprivation. The study sites were then visited by a member of the research team to explain the project needs and requirements and to hold initial discussions around the progress made so far. Data for the study were collected through a combination of audit questionnaires, interviews with key informants, and structured observations of meetings, along with an evaluation of submitted protocols and documents.

An audit tool was developed to capture preliminary information about the existing status of the CDOPs in the study and included information on: population; geography; age range and types of 
deaths; current processes in place for mortality review and responding to unexpected child deaths; the individuals and agencies involved in developing the CDOP; and any factors that had proved instrumental, along with possible barriers and constraints, to development of the CDOP. Each CDOP was visited by two members of the research team who carried out non-participant observation of the panel meeting using a structured proforma. The focus of the observation was on the structure and process of the meeting, rather than on details of the cases discussed. This technique was supplemented by in-depth qualitative interviews with the chair of each CDOP. The interview schedule was designed to clarify the processes and structures involved in developing and running the CDOP, along with the background knowledge and skills necessary for chairing the panel.

A combination of different tools was used to analyse the data. The audit tool, interview transcripts and observation notes were subjected to predominantly qualitative analysis using N-Vivo. The analysis divided into two broad domains: team development, systems and structures; and the process and function of the child death review. Initial scrutiny of the interview transcripts and field notes enabled the research team to develop a coding framework reflecting the key themes identified within each of the two domains. Following coding of the data, different team members analysed the interview data, identifying consistent themes, outriders, and examples of good practice. The outcomes of this further analysis were then discussed by the research team and the wider project steering group allowing the perspectives of different professionals, policy members, and other stakeholders to inform the interpretation of the results. Field notes from the structured observations, along with any protocols, minutes, agendas, and reports supplied by the sites, were reviewed by the research team and compared with the interview data in a process of triangulation. The collated results were distributed to the sites, enabling them to contribute to the interpretation of the results and to question or clarify any issues arising from the analysis.

The project was discussed with the local medical research ethics committee (comparable to an institutional review board), and it was agreed that as an evaluation of those LSCBs which were at the beginning stages of implementing the child death review processes, it fell within the bounds of audit rather than research. Nevertheless, the research team recognised that there were significant issues around confidentiality, with the overview panels themselves and the research team being privy to confidential and identifiable sensitive information. The research team followed strict ethical guidelines agreed in advance with the project steering group and with each site. No identifiable details (names, addresses or specific dates) were recorded in relation to any of the cases discussed. Agreement to the presence of observers at the meetings attended was sought from all members of the panel and all were given the opportunity to ask the observers to leave if particularly sensitive material was being discussed. Participation in the interviews was carried out with fully informed consent of the interviewees. The interview schedules did not require any identifiable client or professional information to be collected. After the field notes and interviews had been transcribed, all transcripts were reviewed by the researcher and project manager to ensure no identifiable data were included.

\section{RESULTS}

The initial questionnaire was distributed to the chairs of all 144 LSCBs operating in England. Sixty responded (42\%), of which 24 indicated a willingness to participate. From these 24 LSCBs, nine sites were selected for the study. Two of these did not manage to establish a CDOP within the timescale of the project. These two sites were nevertheless included in the study to facilitate an understanding of the processes involved in establishing such panels. All nine sites completed the preliminary audit tool (table 1 ).

The audit returns described the demography of the sites, with populations ranging from less than 120000 to nearly 1000000 ; a spread of ethnic groups, with between $1 \%$ and $30 \%$ of the total population belonging to black and minority ethnic groups; and a mix of metropolitan, urban, and rural areas. Where data were provided based on estimates or known childhood deaths, they did not completely match the Office for National Statistics (ONS) data. Discrepancies arose particularly in relation to deaths in the $<28$ days and $15-19$ years age groups.

Interviews were held with the chairs of all nine research sites. A total of nine panel meetings at eight sites were attended by members of the research team. The results from the three main methods of data collection (interviews with chairs, structured observations of panel meetings, and analysis of provided documents) have been combined in a process of triangulation and fall

Table 1 Study sites-data from audit and national statistics

\begin{tabular}{lllllll}
\hline $\begin{array}{l}\text { Study } \\
\text { site }\end{array}$ & $\begin{array}{l}\text { Population } \\
\text { (2001 census) }\end{array}$ & $\begin{array}{l}\text { Ethnicity } \\
\text { (\% black and } \\
\text { minority ethnic) }\end{array}$ & $\begin{array}{l}\text { Deprivation } \\
\text { indices rank } \\
\text { (2001 census) }\end{array}$ & $\begin{array}{l}\text { Child deaths } \\
\text { (20mon/rural mix } \dagger\end{array}$ & $\begin{array}{l}\text { ONS mortality } \\
\text { known to team } \\
\text { in previous year }\end{array}$ & $\begin{array}{l}\text { data from } \\
\text { previous year } \neq\end{array}$ \\
\hline 1 & 977087 & $29.65 \%$ & $15 / 354$ & Metropolitan & 92 & 370 \\
2 & 380615 & $8.17 \%$ & $67 / 354$ & Metropolitan & 50 & 83 \\
3 & 492324 & $2.30 \%$ & $243 / 354$ & $2 / 3$ urban; $1 / 3$ rural & 27 & 85 \\
4 & 118208 & $1.11 \%$ & $21 / 354$ & Urban & 5 & 34 \\
5 & 206814 & $41.23 \%$ & $232 / 354$ & Metropolitan & 27 & Not known \\
6 & 617168 & $10.1 \%$ & $332 / 354$ & Urban/rural & 68 & 111 \\
7 & 216103 & $7.29 \%$ & $12 / 354$ & Metropolitan & 23 & 48 \\
8 & 253800 & $36.98 \%$ & $17 / 354$ & Metropolitan & Not known & 76 \\
9 & 315172 & $2.26 \%$ & $54 / 354$ & Metropolitan/urban & 34 & 77 \\
\hline
\end{tabular}

*The deprivation index used in the 2001 census is a composite index using weighted factors in a number of domains including income employment, education and health. 354 local authority areas were ranked from $1=$ most deprived to $354=$ least deprived. Further information is available at: http://www.neighbourhood.statistics.gov.uk/dissemination/lnfo.do?page=aboutneighbourhood/ indicesofdeprivation/indices-of-deprivation.htm

†For the purposes of the 2001 census, urban areas were defined as those with populations of 20000 people or greater, while metropolitan districts referred to six heavily populated centres including London.

‡The Office for National Statistics (ONS) data are collated data of returns on death certification from the registrars of births, deaths and marriage. 
within a number of themes within two overarching domains: the systems and structures in place to support the child death overview process; and the actual process and function of the panels.

Nine core themes emerged from the data in relation to systems and structures (appendix 1):

- Developing the CDOP - there was a widespread enthusiasm for the process, recognising that this work was challenging but worthwhile; successful implementation depended on the engagement of motivated individuals and good working relationships; lack of understanding or commitment could hinder implementation.

- Purpose-panels recognised the importance of clear purposes and were working to those set out in government guidance; the key purpose was to learn lessons.

- Structure-there were variations in relation to local geography; a degree of flexibility is important.

- Membership-All teams had developed models of core membership with additional co-opted or ad hoc members; optimal team size was between four and 11 members, with public health, coroner's officers, children's social care, police and paediatricians most commonly represented; representatives needed sufficient seniority and experience.

- Team functioning - an atmosphere of trust was considered particularly important given the sensitive nature of this work; multi-agency working can, however, be challenging; chairs could come from a range of backgrounds and needed generic chairing skills but also needed support from members with specific expertise.

- Protocols and procedures-protocols were considered important but had not been fully developed.

- Relationship with other processes-the overlap with other processes, including more in-depth Serious Case Reviews, was an important area, but had not been fully clarified by any of the teams.

- Resources-panels require sufficient resource to function effectively; this includes funding of key administrative staff and processes, professionals' time, and training costs.

- Audit and governance-systems of audit and governance were important but had not been developed. Six themes emerged in relation to process and function (appendix 2).

- Criteria for review-panels recognised their responsibility to review all deaths, but most felt that not all deaths could be reviewed to the same depth.

- Data processing-panels relied on multiple sources of notification; the most helpful approaches to data collection combined a limited data set of categorical information supplemented by narrative information; data collection and review is time consuming.

- Liaison and information sharing-different approaches to information sharing, confidentiality, and data protection were observed; some panels anonymised information before the review; no panels had yet involved parents in the review process.

- Team meetings-frequency of meetings varied from monthly to every 3 months; $3-5$ cases appeared an optimum number to discuss in a $2-3 \mathrm{~h}$ meeting; panel meetings worked best when members were provided with collated information before the meeting, rather than relying on original case records.

- Analysis - at this stage few panels had developed any formal frameworks or systems for analysis.

- Outcomes - the main emphasis was on learning broad lessons from all deaths rather than individual case issues; panels anticipated producing an annual report.
Our observations and the interview data emphasised the importance of child death review being a multidisciplinary process involving professionals of sufficient seniority to be able to analyse and make sense of the information being presented; that the process was resource intensive with time needed not only for the panel meetings, but also for preparation by all panel members; that effective analysis requires both quantitative and qualitative (narrative) information, and is best achieved through a structured analytic framework; and that the focus should be on learning lessons from the deaths, not on trying to apportion blame.

At the nine panel meetings attended by members of the research team, a total of 24 cases were discussed in detail, with between two and seven cases discussed in each. The ages of the children discussed ranged from 2 days to 19 years, with 10 aged $<1$ year, five between 1-6years, and nine teenagers (15-19 years). Five of the cases were deaths related to prematurity or congenital abnormalities; seven others involved children dying of other natural causes (two of whom were severely disabled children), five deaths were from external causes (including one road traffic death, two drownings, and two deaths from choking), three were unexplained infant deaths, and a further four cases were near misses from deliberate self harm or assault (table 2).

In 17 of the 24 cases issues were raised that may have indicated preventable factors in the child or young person themselves; the parents or carers; the environment; or service provision. Even though the panels were at an early stage of development, a number of examples of recommendations and action relating to injury prevention were observed (table 3).

\section{DISCUSSION}

At the time this study was undertaken, child death review was in its infancy in the UK. Although there were well established hospital mortality review processes, and in-depth enquiries into maltreatment related deaths (Serious Case Reviews), the concept of a broader multi-agency approach to reviewing all childhood deaths had not been established. Drawing on lessons from child death review in the USA and elsewhere, the Department for Children, Schools and Families mandated the establishment of multi-agency CDOPs in each local authority area in England. This was backed up with new government funding of $£ 52$ million ( $€ 62$ million, US\$80 million) over 3 years through both health and local authorities, and with the development of national guidance ${ }^{1}$ and training materials ${ }^{9}$ to support their introduction. Through this study we were able to observe the experience of a small number of 'early starter' CDOPs and to use their experience to help guide and support the further development of these processes across England. The introduction of these processes across England was further supported through a series of regional seminars at which the results of this study were presented, allowing other panels to learn from the experience of the early starters.

Our study highlighted a number of issues involved in establishing these panels. In all of the panels observed, a lot of effort had gone into developing the structures and processes even before any deaths could be reviewed, sometimes taking many months of negotiation and planning. In some instances the panels were still focused on development issues and this introduced delays into the review of deaths. It was clear that reviews could not be effectively carried out without clear structures and processes for gathering and using data and for the subsequent steps of making effective recommendations. With that in mind, we feel it is worth investing time and resources into the initial 
Table 2 Cases reviewed in the observed panel meetings

\begin{tabular}{|c|c|c|c|}
\hline & Child's age & Cause of death/incident as determined by the panel & Issues identified \\
\hline \multicolumn{4}{|c|}{ Deaths } \\
\hline 1 & 2 days & Extreme prematurity, twin & No issues identified \\
\hline 2 & 2 days & Extreme prematurity, twin & No issues identified \\
\hline 3 & 2 weeks & Congenital heart defect & No issues identified \\
\hline 4 & 25 days & Multiple congenital abnormalities; twin & Issues around support / monitoring of twin \\
\hline 5 & 1 month & Tracheo-oesophageal fistula & No issues identified \\
\hline 6 & 2 months & Sudden unexpected death in infancy (SUDI) & Initial concerns re welfare of siblings \\
\hline 7 & 2 months & Meningitis & $\begin{array}{l}\text { Issues around speed of medical response; discussed with } \\
\text { hospital staff }\end{array}$ \\
\hline 8 & 6 months & Choking & Possibility of neglect raised but discounted. \\
\hline 9 & 8 months & Unclear; premature & Issues around domestic violence \\
\hline 10 & 9 months & SUDI & Paternal alcohol use and co-sleeping \\
\hline 11 & 15 months & Choking & No issues identified \\
\hline 12 & 2 years & Cancer: expected death & No issues identified \\
\hline 13 & 2 years & Multi-organ failure secondary to epilepsy & Missed appointments \\
\hline 14 & 3 years & Drowning abroad & Issues around safety of children in swimming pools abroad \\
\hline 15 & 6 years & Drowning abroad & Issues around safety of children in swimming pools abroad \\
\hline 16 & 15 years & Sudden collapse: presumed cardiac arrhythmia & $\begin{array}{l}\text { Coroner not holding an inquest; issues around school safety } \\
\text { and response of services }\end{array}$ \\
\hline 17 & 16 years & $\begin{array}{l}\text { Pneumonia and multiple organ failure; severe disabilities; } \\
\text { expected death }\end{array}$ & No issues identified \\
\hline 18 & 17 years & Road traffic accident & Alcohol and drug use \\
\hline 19 & 17 years & Gastroenteritis & Possible issues around primary care provision \\
\hline 20 & 19 years & $\begin{array}{l}\text { Died during cardiac catheterisation; severely disabled } \\
\text { young person }\end{array}$ & $\begin{array}{l}\text { Outside standard age range, but considerable involvement } \\
\text { of children's health and social care services }\end{array}$ \\
\hline \multicolumn{4}{|c|}{ Near miss incidents } \\
\hline 21 & 13 years & Near miss: deliberate self harm & Connection with case 22 \\
\hline 22 & 15 years & Near miss: deliberate self harm (DSH) & $\begin{array}{l}\text { Child behaviour issues; provision of secure places; } \\
\text { management of severe DSH; awareness raising }\end{array}$ \\
\hline 23 & 15 years & Near miss: deliberate self harm & Connection with case 22 \\
\hline 24 & 17 years & Near miss: serious assault & Criminal investigation ongoing \\
\hline
\end{tabular}

development of the panel, and that this should be separated out from the panel working itself. The individuals involved in the study emphasised the importance of having local champions to drive the process forward, so that it is seen as something worthwhile for improving children's safety and well-being, rather than a bureaucratic exercise; of engaging a wide range of stakeholders in scoping and setting up the panels; and for good induction and training of the panel members. Overwhelmingly panel members conveyed a sense that they considered this process to be worthwhile and to carry enormous potential for improving children's lives.

The panels studied were at an early stage of development of their processes and recognised that they were unlikely to have full notification of deaths in their area. This was highlighted by the discrepancies between the ONS death registration data and the panel notification data (table 1). In particular, many panels were not being notified of perinatal deaths or of later adolescent

Table 3 Outcomes from case reviews related to injury prevention

\begin{tabular}{ll}
\hline Case & Recommendations and action \\
\hline Two drowning deaths abroad & $\begin{array}{l}\text { Production of a safety leaflet for families } \\
\text { travelling with children }\end{array}$ \\
3 'near miss' cases of deliberate & $\begin{array}{l}\text { A collaborative project between mental } \\
\text { health and education services to raise } \\
\text { self harm }\end{array}$ \\
$\begin{array}{l}\text { awareness in schools, train and support } \\
\text { teachers in prevention, and develop a joint } \\
\text { agency protocol for responding to } \\
\text { deliberate self harm } \\
\text { Review of local policies on servicing of } \\
\text { gas appliances in social housing }\end{array}$ \\
$\begin{array}{l}\text { monoxide poisoning } \\
\text { Death of a disabled child in a special }\end{array}$ \\
school following a choking episode & practices \\
\hline
\end{tabular}

deaths. The introduction of statutory guidelines with a duty to report should improve this coverage. At the time of the study, the major focus was on establishing membership and remits of the panels, and systems for gathering and storing the data. Although the focus was on learning lessons and taking action to prevent future child deaths, there was very little awareness of different methods for analysis of data and formulation of recommendations. Some preliminary ideas emerged from some of the panels, but this is an area that requires further research, development, and training. As this was an observational study focused on understanding the experience and process of child death review, we were unable to follow-up on any recommendations coming from the panels. As child death review processes become more established there is an urgent need for robust evaluations of the outcomes and effectiveness of these processes, with clearly defined outcome measures and standards.

In spite of these limitations, we were able to observe a number of significant actions coming from the cases reviewed, including public awareness campaigns, community safety initiatives, training of professionals, development of protocols, and lobbying of politicians. The examples seen emphasised the potential for these panels to be significant drivers for safeguarding children's welfare. The engagement of public health and professionals from other agencies involved in injury prevention was seen as crucial to the success of these panels, although the degree of engagement varied between the sites studied. At the time of the study, most arrangements seemed to be ad hoc, although there appeared to be a commitment to collaborative working to identify and respond to risks to children's safety and welfare. The involvement of parents in review processes was considered important by many participants, but 
Box 1 Recommendations for developing child death overview panels (CDOPs)

1. New child death overview panels should be established in accordance with any national guidance, taking account of the local situation and in consultation with neighbouring areas.

2. Each panel should define their terms of reference, to include the purposes and functions of the panel, membership, chairing and administration, relationships with other processes, information sharing, outputs and lines of accountability.

3. The CDOP should have a core membership, with representatives of the local key agencies, including public health, paediatrics, social care, and police as a minimum. The core membership may be supplemented by co-opted members from other disciplines.

4. Panels should consider how they can appropriately include lay representatives.

5. Panels should establish mechanisms for appropriately informing and involving parents and other family members in the child death review process.

6. Each panel should appoint an administrative team to support its working.

7. CDOPs should meet on a regular basis to review all deaths of children normally resident in their area.

8. Each panel should establish operational procedures for the smooth running of the child death review processes and should monitor their implementation and output. This will include procedures for notification, information gathering, collation and analysis of the information gained, overviews of all deaths, and outcomes.

9. Each panel should establish systems for safe storage and use of data gathered for the child death overview processes.

10. Each panel should ensure that training is provided for all members, including co-opted members.

11. Each panel should monitor the function and outcomes of its CDOP and any related processes and should have clear accountability to an overseeing organisation or agency.

none had developed effective systems for doing so. Most participants did not anticipate inviting bereaved parents to panel meetings, but felt that there should be a system allowing them to contribute information or questions and to receive feedback from the panel.

There was recognition among the study sites of the need for different levels of review. England already has well established systems for Serious Case Reviews into deaths from abuse or neglect. Such deaths require a more in-depth review of interagency working and child protection procedures which can sit alongside a broader review of the wider circumstances and patterns of all child deaths.

This study was a small, predominantly qualitative study of early starter sites in England. Only 24 of the 144 LSCBs in England responded indicating a willingness to participate. The early starter sites selected may represent those that were particularly motivated to introduce child death review, and this may not be replicated where the processes are imposed on a local team. The processes being developed have to be interpreted in the social and political context, and the advances seen since then could not have been achieved without the investment of time, resources, and training. While many of the specific approaches

\section{What is already known on this subject}

- Child death review has been operating in parts of the USA since the 1970s and 1980s.

- There is some evidence that child death reviews can be effective in providing contemporary information on patterns of child death and promote action to prevent child deaths.

- To date there has been only limited experience of child death review in the UK.

\section{What this study adds}

- Observations of 'early starter' panels have helped inform the introduction of child death review processes across England.

- To operate effectively, these panels need a clear remit and purpose, robust structures and processes, and committed personnel.

- The multi-agency nature of the panels supports a broader approach to understanding and responding to children's deaths than one located within health alone.

may not translate to other situations, the general principles to emerge from the qualitative analysis could apply to any emergent systems for child death review. Within the scope of this study, we were not able to observe or comment on any outcomes from child death review. Ultimately the effectiveness of child death review processes must be judged by their impact on outcomes for children, but this will require more detailed and long term studies.

The findings of our observational study enabled us to make a number of recommendations to assist LSCBs in establishing new CDOPs (box 1).

\section{CONCLUSIONS}

Through the Children Act (2004) and subsequent statutory guidance, England has become the first country in the world to establish a mandated national approach to reviewing all child deaths. The results of this study of 'early starter' CDOPs has helped to inform the subsequent establishment of panels across England. To operate effectively, these panels need a clear remit and purpose, robust structures and processes, and committed personnel. It is our view that the multi-agency nature of the panels supports a broader approach to understanding and responding to children's deaths than one located within health alone. There is some evidence that these reviews can lead to appropriate recommendations to promote children's safety and welfare. Further work is required, however, to establish whether these recommendations do in fact lead to effective action and positive outcomes for children.

Acknowledgements The authors would like to acknowledge the help of Dr Shahid Perwez in collecting and analysing data for this study and of Ms Michelle Oldfield in her administrative support. We would also like to thank the chairs and members of the nine panels involved in the study.

Funding The study was funded by the Department for Children, Schools and Families (formerly Department for Education and Skills). This funding was awarded in open tender and the Department had no involvement in the study design, conduct or analysis. The views expressed in this paper are those of the authors and do not necessarily represent those of the Department for Children, Schools and Families. 
Competing interests None.

Contributor All authors were fully involved in all aspects of the study, including visiting and observing the panels and analysing the data. Dr Sidebotham produced the first draft of the paper, and all other authors reviewed and commented on drafts in preparation.

Provenance and peer review Not commissioned; externally peer reviewed.

\section{REFERENCES}

1. HM Government. Working Together to Safeguard Children. London: Department for Education and Skills DfES, 2006.

2. HM Government. Children Act 2004. London: The Stationery Office, 2004.

3. Durfee M, Durfee DT, West MP. Child fatality review: an international movement. Child Abuse Negl 2002:26:619-36.

4. Bunting $\mathbf{L}$, Reid C. Reviewing child deaths-learning from the American experience. Child Abuse Review 2005;14:82-96.

5. Rimsza ME, Schackner RA, Bowen KA, et al. Can child deaths be prevented? The Arizona Child Fatality Review Program experience. Pediatrics 2002;110:e11.

6. Onwuachi-Saunders C, Forjuoh SN, West $P$, et al. Child death reviews: a gold mine for injury prevention and control. Inj Prev 1999;5:276-9.

7. Gellert GA, Maxwell RM, Durfee MJ, et al. Fatalities assessed by the Orange County child death review team, 1989 to 1991. Child Abuse Negl 1995:19:875-83.

8. Sidebotham P, Fox J, Horwath J, et al. Preventing childhood deaths: an observational study of child death overview panels in England. London: Department for Children, Schools and Families, 2008.

9. Sidebotham P, Fleming P, Fox J, et al. Responding when a child dies (CD Rom). London: Department for Children, Schools and Families, 2008.

\section{APPENDIX 1 CORE THEMES AND ISSUES IN RELATION TO SYSTEMS AND STRUCTURES}

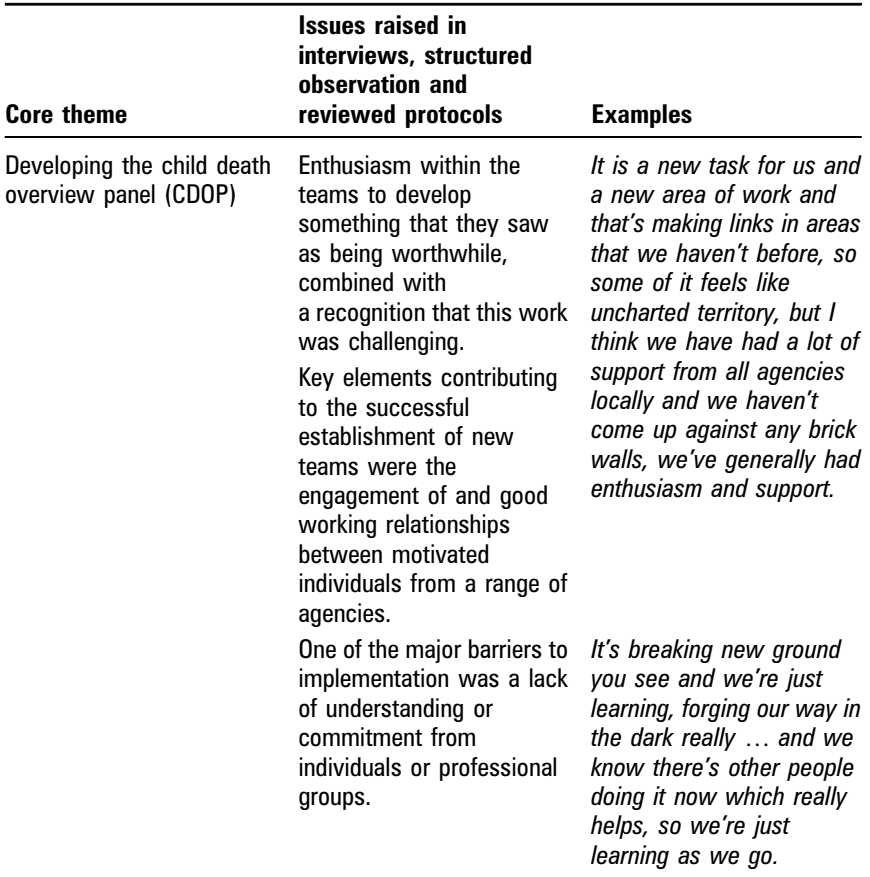

Continued

Continued

\begin{tabular}{ll}
\hline & $\begin{array}{l}\text { Issues raised in } \\
\text { interviews, structured } \\
\text { observation and } \\
\text { reviewed protocols }\end{array}$ Examples \\
Core theme
\end{tabular}

Purpose

Although all panels thought I think people ... will need it important to have a clear to understand what's the purpose or remit, few had purpose of CDOP... so it's set those out. not just seen as a chore The purposes as set out in that is a government government guidance were imposed initiative, but that felt to be appropriate.

it actually has a benefit in what we're trying to achieve.

Most saw the purpose of the CDOP in terms of learning lessons and were keen that it should not become an exercise in apportioning blame.

to gain an understanding of the circumstances of the child's life, including the possibility of abuse or neglect land thus providing a safety net to identify possible Serious Case Reviews). One output will be the learning of common lessons which will be useful in the formulation of public health strategies.

Structure

Membership developed models of core
membership with
additional co-opted or adhoc members.

Of the nine panel meetings observed, there were between 4 and 11 members present, with one outlier of 22 members.

Professionals most commonly included as core members were public health, coroner's officers, children's social care police and paediatricians with education, drug and alcohol teams, child and adolescent mental health and adult mental health typically participating as co-opted members.

Most sites considered it important to have experienced and credible representatives on the panel.

Independence was felt to be important but difficult to achieve; some panels were looking at models for incorporating lay or parent membership.
If (the Safeguarding Board)

is co-terminous with

a Primary Care Trust,

you've got the links there with general practitioners ... You're looking at ideally co-terminosity with your local health service provider which is a bit more difficult but you're about making the process work by having sensible boundaries and sensible geography.

What we'll have is a core membership and then an invited membership according to the nature of the cases to be discussed... We don't envisage that you have all those people there all the time, but we have a core group, and... a middle group who will be called upon regularly and then there will be a team of liaison people around each agency who will then feed the information and may come in for a particular single case rather than for a whole panel meeting.

I think there has got to be a credibility, that the people who are going to sit on the panel will be people who are experienced enough in understanding the issues... it's not someone coming for a learning experience, it's someone who's got a richness of experience to both analyse and contribute and provide some leadership. 
Continued

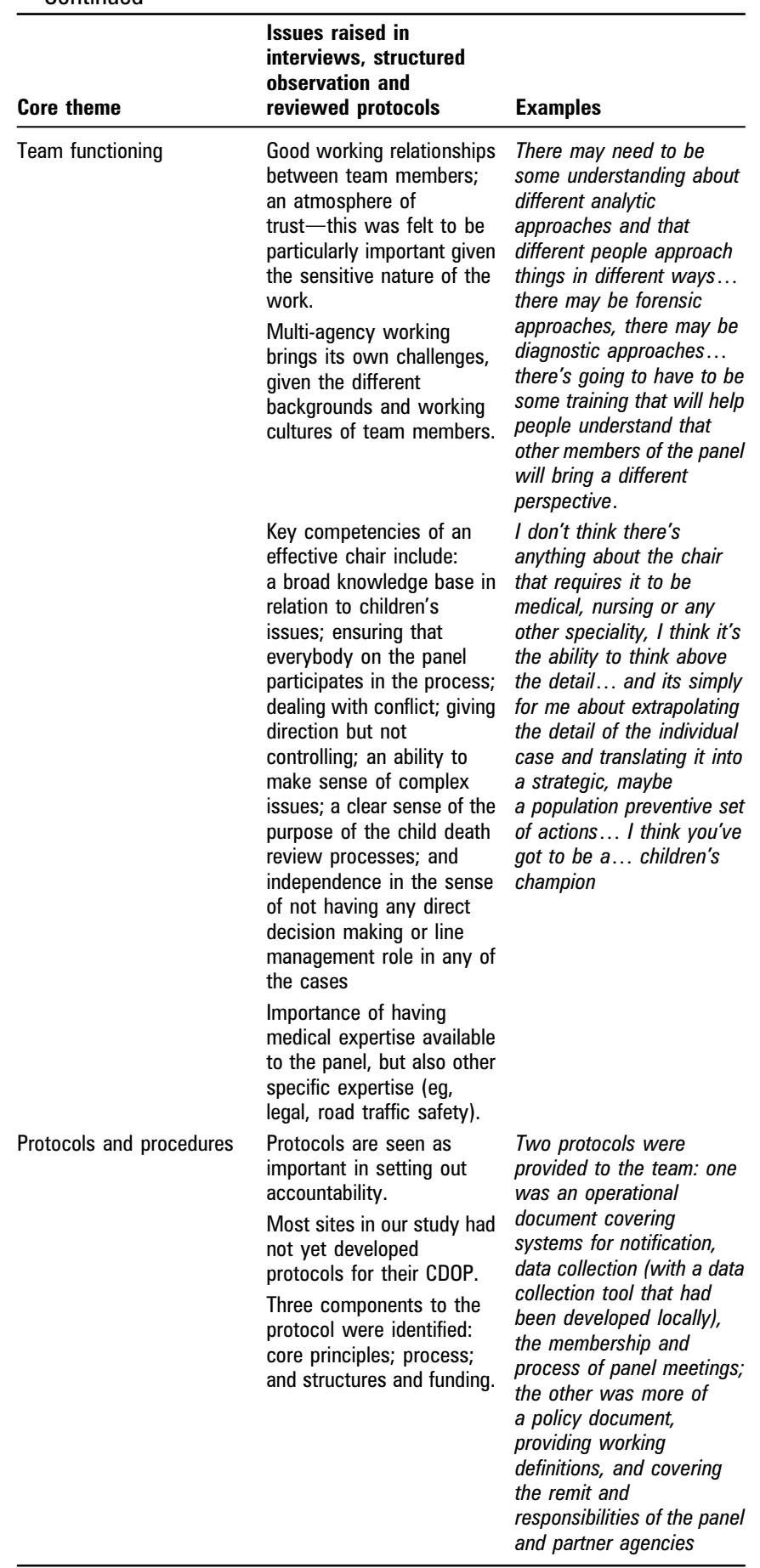

Continued

Continued

\begin{tabular}{lll}
\hline & $\begin{array}{l}\text { Issues raised in } \\
\text { interviews, structured } \\
\text { observation and } \\
\text { reviewed protocols } \quad \text { Examples }\end{array}$ \\
Core theme &
\end{tabular}

Relationship with other The overlap with Serious The internal reviews that

processes Case Reviews (into deaths are already happening in from abuse or neglect) was many hospitals... and have seen as important, but it been running for sometime, was not clear how the two but they have two very functioned together; Serious Case Reviews were seen as more intensive and time consuming.

The rapid response process for unexpected child deaths, including a final local case discussion, is an operational response to individual cases; it should feed into the child death overview panel, which has a broader remit.

The CDOP differs from individual agency management reviews, or hospital based mortality reviews.

Surprisingly, none of the interviewees mentioned the relationship between the CDOP and the Coroner's inquest. This was felt by the study team to be an important area.

Resources

Audit and governance
Financial: funding of key administrative staff and processes; time costs of professionals on the panels; training costs.

Personnel: three crucial roles were identified-panel chair, coordinator or manager, and administrator.

Professional time was considerable and had to be resource issue I could put fitted in among all the other on the table in relation to time pressures; professionals needed time to attend the panels but also to prepare for the panel meetings and to take actions afterwards.

Systems of audit and governance were not well developed but were considered important. Included lines of accountability and reporting to Local Safeguarding Children Boards and individual constituent agencies Issues of confidentiality and data security were raised, but many panels had not yet found ways to address these different, requirements. One is to have a bird's eye view of all deaths within the district and the other is part of the internal hospital governance arrangements and therefore different information needs to be provided for each setting, you can't necessarily use the same information for both. So getting people's heads clear around that, particularly when they've been in the habit of running mortality meetings whether that's intensivists or neonatologist or whole hospital arrangements, and shifting sideways and taking the emphasis off the medical bits and did the SHO get out of bed or did somebody write down the pulse rate, towards collecting wider information about, when did this mother book for antenatal care, or what do we know about father's drug use.

It takes a lot of time, I would say every meeting, the meetings usually last two hours... but they are usually preceded by, I would say, at least twelve hours of my time just collecting data.

I suppose the only this, is that this group sits alongside a million others, so your day job is stretched now that's the issue really.

This is central to the working of the Safeguarding Board, but it's a new piece of work I guess each meeting will have to have a way of evaluating its work rather than waiting and looking back retrospectively over 6 months work. I think I would want a system whereby at the end of each meeting the panel actually reviewed what, how well do we think we've achieved what we set out to achieve today and then it would aggregate those up, into a quarterly kind of process. 
Continued

\begin{tabular}{|c|c|c|}
\hline Core theme & $\begin{array}{l}\text { Issues raised in } \\
\text { interviews, structured } \\
\text { observation and } \\
\text { reviewed protocols }\end{array}$ & Examples \\
\hline \multirow[t]{4}{*}{ Team Meetings } & $\begin{array}{l}\text { The frequency of panel } \\
\text { meetings varied from } \\
\text { monthly to every } 3 \text { months; } \\
3-5 \text { cases appeared an } \\
\text { optimum number to } \\
\text { discuss in a } 2-3 \mathrm{~h} \\
\text { meeting, with } 20-30 \text { min } \\
\text { spent discussing each } \\
\text { case. }\end{array}$ & $\begin{array}{l}\text { We are settling into } \\
\text { a pattern about once every } \\
3 \text { months and you can see } \\
\text { that there's usually five or } \\
\text { six cases plus the following } \\
\text { up of matters arising from } \\
\text { previous minutes. }\end{array}$ \\
\hline & $\begin{array}{l}\text { Time needs to be set aside } \\
\text { for preparation before the } \\
\text { meeting; panel members } \\
\text { need to be provided with } \\
\text { succinct, collated } \\
\text { information on each case } \\
\text { sufficiently in advance of } \\
\text { the meeting to allow them } \\
\text { to read the reports and } \\
\text { come prepared. }\end{array}$ & $\begin{array}{l}\text { A lot of thought has to go } \\
\text { into, into agenda setting. } A \\
\text { huge amount of thinking } \\
\text { and like we spend an hour } \\
\text { and a half preparing for } \\
\text { today's meeting... it's that } \\
\text { thinking, getting [the } \\
\text { paediatrician] out of his } \\
\text { clinical area and getting his } \\
\text { brain and thinking it } \\
\text { through really carefully and } \\
\text { then, that's really } \\
\text { important. }\end{array}$ \\
\hline & $\begin{array}{l}\text { Relying on original case } \\
\text { records at the meeting can } \\
\text { be counterproductive as it } \\
\text { takes time and distracts } \\
\text { from learning lessons and } \\
\text { focusing on key issues. }\end{array}$ & $\begin{array}{l}\text { In one observed meeting, } \\
\text { a member of the Primary } \\
\text { Care Team had been } \\
\text { invited but was unable to } \\
\text { attend the meeting. } \\
\text { However, the child's }\end{array}$ \\
\hline & $\begin{array}{l}\text { There were apparent } \\
\text { dangers in spending too } \\
\text { long discussing each case, } \\
\text { in effect carrying out an } \\
\text { investigation into the } \\
\text { child's death rather than } \\
\text { focusing on lessons to be } \\
\text { learnt. }\end{array}$ & $\begin{array}{l}\text { medical notes were lent to } \\
\text { the children's social care } \\
\text { delegate for use by the } \\
\text { CDOP. Not unusually, these } \\
\text { notes were very thick, } \\
\text { unwieldy and full of } \\
\text { complicated medical } \\
\text { jargon. No-one had the } \\
\text { relevant expertise to } \\
\text { properly interpret the notes } \\
\text { and a great deal of time } \\
\text { was wasted while different } \\
\text { delegates tried to decipher } \\
\text { the text. }\end{array}$ \\
\hline \multirow[t]{3}{*}{ Analysis } & $\begin{array}{l}\text { At this stage, few of the } \\
\text { panels had developed any } \\
\text { formal frameworks or } \\
\text { systems for analysis. }\end{array}$ & \multirow{3}{*}{$\begin{array}{l}\text { [Our panel uses a] multi- } \\
\text { axial approach to individual } \\
\text { deaths so, sort of medical } \\
\text { factors, social factors, } \\
\text { environmental factors and } \\
\text { whether they were a major } \\
\text { fact, a minor fact or no } \\
\text { relevance at all. }\end{array}$} \\
\hline & $\begin{array}{l}\text { There is a balance between } \\
\text { ensuring enough } \\
\text { information is available in } \\
\text { a timely manner to make } \\
\text { sense of the circumstances } \\
\text { of the death, but not too } \\
\text { much so as to overwhelm } \\
\text { the process and delay } \\
\text { learning lessons. }\end{array}$ & \\
\hline & $\begin{array}{l}\text { A number of participants } \\
\text { highlighted the importance } \\
\text { of regional or national } \\
\text { collation of data and } \\
\text { learning lessons at a wider } \\
\text { level }\end{array}$ & \\
\hline
\end{tabular}

Continued

\begin{tabular}{|c|c|c|}
\hline Core theme & $\begin{array}{l}\text { Issues raised in } \\
\text { interviews, structured } \\
\text { observation and } \\
\text { reviewed protocols }\end{array}$ & Examples \\
\hline \multirow[t]{2}{*}{ Outcomes } & $\begin{array}{l}\text { Most of the panels } \\
\text { anticipated producing an } \\
\text { annual report to go to the } \\
\text { Local Safeguarding } \\
\text { Children Board, with or } \\
\text { without separate reports } \\
\text { on each case or panel } \\
\text { meeting. }\end{array}$ & $\begin{array}{l}\text { I think we would have } \\
\text { a small summary report for } \\
\text { each of the unexpected } \\
\text { deaths... like a kind of } \\
\text { closure on that piece of } \\
\text { analysis... it would be } \\
\text { what are the learning } \\
\text { points from talking about }\end{array}$ \\
\hline & $\begin{array}{l}\text { The main emphasis was on } \\
\text { learning broad lessons } \\
\text { from all deaths, rather than } \\
\text { individual case issues } \\
\text { which should be dealt with } \\
\text { in other ways. }\end{array}$ & $\begin{array}{l}\text { child } A \text { or child } B \text {, and then } \\
\text { they would be, something } \\
\text { that we could aggregate up } \\
\text { into our annual report } \\
\text { which would be about the } \\
\text { overall learning. }\end{array}$ \\
\hline
\end{tabular}

A number of specific outcomes came out of the cases observed, even at this very early stage.

First of all looking at the individual child and whether in terms of the individual child we've actually covered all bases in terms of ongoing services for them where appropriate. And that means asking about child protection issues, are they dealt with, are they still live, are they ongoing, and are those support services going in... The second thing is the more global issue to do with broader [issues], so this is the system, the kind of systematic thinking that you might be looking for... to look at the... more global issues that affect the broader population, not jus the individual child... and

then the third thought... was about awareness raising and training.

It was perceived that the At the time no-one would CDOP provided a forum for take responsibility for it taking forward issues raised in respect to child safety.

[the dangers of children falling out of open windows]. The

Safeguarding Board wasn't in this mode, the

Community Safety

Partnership was not interested because it wasn't a crime. ROSPA... wasn't interested because it wasn't a road traffic accident... so we had got nowhere to go with it.

Whereas now we would say, we're a Safeguarding Board, actually this is our problem, we now have that responsibility so we need to do something about it... 